\title{
Varied Reports of Adult Transgender Suicidality: Synthesizing and Describing the Peer-Reviewed and Gray Literature
}

\author{
Noah Adams, ${ }^{1, *}$ Maaya Hitomi, ${ }^{2}$ and Cherie Moody ${ }^{3}$
}

\begin{abstract}
Purpose: This article reports on the findings of a meta-synthesis undertaken on published gray transgender suicidality literature, to determine the average rate of suicidal ideation and attempts in this population.

Methods: Studies included in this synthesis were restricted to the 42 that reported on 5 or more Canadian or U.S. adult participants, as published between 1997 and February 2016 in either gray or peer-reviewed health literature. Results: Across these 42 studies an average of $55 \%$ of respondents ideated about and $29 \%$ attempted suicide in their lifetimes. Within the past year, these averages were, respectively, $51 \%$ and $11 \%$, or 14 and 22 times that of the general public. Overall, suicidal ideation was higher among individuals of a male-to-female (MTF) than female-tomale (FTM) alignment, and lowest among those who were gender non-conforming (GNC). Conversely, attempts occurred most often among FTM individuals, then decreased for MTF individuals, followed by GNC individuals.

Conclusion: These findings may be useful in creating targeted interventions that take into account both the alarmingly high rate of suicidality in this population, and the relatively differential experience of FTM, MTF, and GNC individuals. Future research should examine minority stress theory and suicidality protection/resilience factors, particularly transition, on this population.
\end{abstract}

Keywords: transgender; suicide; marginalization

\section{Introduction}

In recent years, transgender individuals have rapidly gained visibility. Despite this, they continue to be at risk for negative life events that adversely affect their health and well-being, such as being rendered invisible, experiencing isolation, and being subjected to societal violence. ${ }^{1}$ Perhaps as a result, current and past studies report appallingly high rates of suicidality (attempts and ideation) in this population. For instance, Scanlon et al., ${ }^{1}$ reported an attempt rate of $43 \%$ and an ideation rate of $77 \%$ among transgender Ontarians, compared to $0.5 \%$ and $3.7 \%$, respectively, in the general population. $^{2,3}$ Unfortunately, the applicability of these findings in guiding policy and future research is impacted by wide variation in the findings of suicidality rates. ${ }^{4,5}$ For example, Xavier et al. ${ }^{6}$ report an attempt rate of $25 \%$ and an ideation rate of $65 \%$, while Imbimbo et al. $^{7}$ record rates of $3 \%$ and $50 \%$, respectively. The current meta-synthesis attempts to address these discrepancies by measuring the overall variation across and averaging the suicidality rates within these studies. This knowledge may encourage the creation of targeted and strategic mental health interventions and research.

\section{Literature review}

Historical trends. The field of transgender healthcare has been described by Bockting ${ }^{8}$ as evolving from utilizing a disease-based lens of transgender health and behavior to an identity-based lens. Within this framework, and as confirmed by our literature review, the

\footnotetext{
${ }^{1}$ Faculty of Health Professions, School of Social Work, Dalhousie University, Halifax, Nova Scotia, Canada.

${ }^{2}$ Applied Social Psychology, College of Arts and Science, University of Saskatchewan, Saskatoon, Saskatchewan, Canada.

${ }^{3}$ Educational and Counselling Psychology, Faculty of Education, McGill University, Montreal, Quebec, Canada.
}

*Address correspondence to: Noah Adams, MSW, Faculty of Health Professions, School of Social Work, Dalhousie University, Halifax, Nova Scotia M5A4K5, Canada, E-mail: noah@noahjadams.com

(C) Noah Adams et al. 2017; Published by Mary Ann Liebert, Inc. This Open Access article is distributed under the terms of the Creative Commons License (http://creativecommons.org/licenses/by/4.0), which permits unrestricted use, distribution, and reproduction in any medium, provided the original work is properly credited. 
disease-based lens appears to have been prevalent from 1953, when the first report on transgender suicidality was published ${ }^{9}$ until roughly 1997 . This period was characterized by research that viewed transgender health and identity as fundamentally psychopathological, deviant, and manipulative. ${ }^{10-13}$ Despite no empirical support, many healthcare professionals tended to view suicidality as a manipulative tactic to force surgery, ${ }^{14}$ which would invariably lead to poor mental health outcomes, such as suicide and psychotic breakdown. ${ }^{15}$ In fact, evidence existed that suggested the opposite: that improvement tended to be drastic following surgery. ${ }^{16}$

The utilization of an identity-based lens appears to have begun to overtake the disease-based lens in roughly 1997, with the publication of Devor's ${ }^{17}$ seminal study on female-to-male (FTM) transsexuals. The identity-based lens is characterized by the assumption that transgender identity is part of a natural spectrum that includes identities beyond those that are male or female, feminine or masculine. ${ }^{8}$ Proponents of this lens argue that physical and psychological stress, resultant from institutional and societal discrimination, are major contributors to suicidality in this population. ${ }^{1,18,19}$

While the disease-based lens continues to be used, ${ }^{8}$ particularly outside of North America, ${ }^{20}$ there is increasing disagreement as to whether the cause of transgender identity is mental, hormonal, biological, and/or genetic. $^{21}$ Similarly, suicidality in this population is variously attributed to psychopathology, neurobiology, ${ }^{22}$ and/or antitransgender stigma. ${ }^{19}$

Meta-analyses and systematic reviews. Ten systematic reviews or meta-analyses have mentioned suicidality among transgender people; however, only Marshall et al., ${ }^{23}$ approached this as the primary question and was designed to include all articles on transgender suicidality. Nevertheless, although an important contribution to the literature and even accounting for the parameters of their review, Marshall et al. ${ }^{23}$ appear to have missed several studies (numbers 2, 5-11, 16, 19$21,23-26,32-33,35$, and 42 in Table 1), and counted a single research project three times (37 in Table 1).

The remaining nine reviews and meta-analyses, while important, largely address transgender suicidality as a secondary question in relation to other issues, such as HIV or geographical location. As such, these articles do not encompass the breadth of transgender suicidality literature addressed in this meta-synthesis. For example Meads et al. ${ }^{91}$ restricts itself to one region in England, while Herbst et al. ${ }^{92}$ focuses primarily on
HIV prevalence and risk factors which, though common in this field, is not reflective of all transgender individuals. ${ }^{21}$ Finally, the articles by Pauly, ${ }^{93-96}$ the Wessex Institute for Health Research and Development, ${ }^{97}$ and Lundström et al. ${ }^{98}$ address transgender suicidality vis-a-vis the impact of gender confirmation surgery, finding the persistently held notion that transgender individuals experience higher rates of suicidality after gender confirming surgery to be unfounded (indeed, suicidality has been recorded to be most common when requests for surgery are refused). ${ }^{15}$

\section{Method}

Eligibility criteria

All studies included in this meta-synthesis reported data from original participant research investigating transgender suicide attempts and/or ideation. Both gray and peer-reviewed academic literature were included, as the former allowed for a larger data pool and helped to reduce the impact of publication bias, where research with nonsignificant findings may be published in a thesis, but not a peer-reviewed journal. Studies were included if they were published in English-language North American (Canada and the United States) journals, between 1997 and February 1, 2016. These studies must also have reported quantitative data on suicidality among five or more transgender participants with a diagnosis of gender dysphoria and/or self-identification as transgender. Further, the majority $(50 \%+1)$ of participants must have been 18 years or older at the time of participation.

Additionally, a word about the inclusion of crossdressers (CDs). It is noted that there are many terms used by transgender individuals to define their experience of gender and gender identity. ${ }^{65,99}$ The term CD, which identifies individuals "who dress in clothing or express their gender in ways that society deems inconsistent with the sex they were assigned at birth" is commonly used for this purpose. ${ }^{99}$ In the case of this study, CDs are included because they answered research calls for transgender people and because in most cases this identity cannot be assumed to be exclusive of other transgender identities.

Studies were excluded if they reported only on completed suicides or nonsuicidal self-injury, single case reports, or included a transgender cohort as part of a larger population (e.g., LGB) without providing discrete transgender data. This includes reports that referenced, but did not provide data on investigations into transgender suicidality. Additionally, research that resulted in multiple publications was only counted 


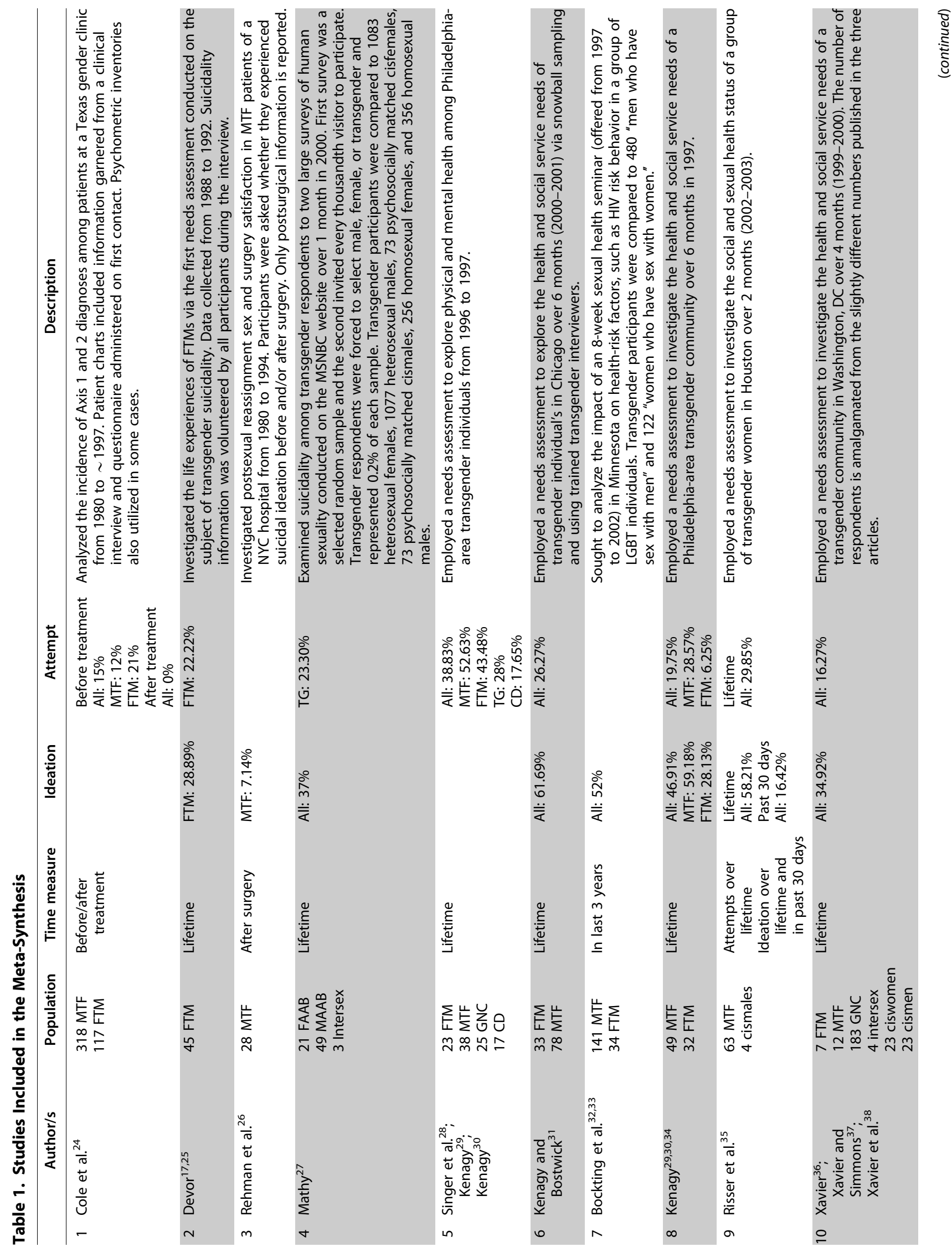




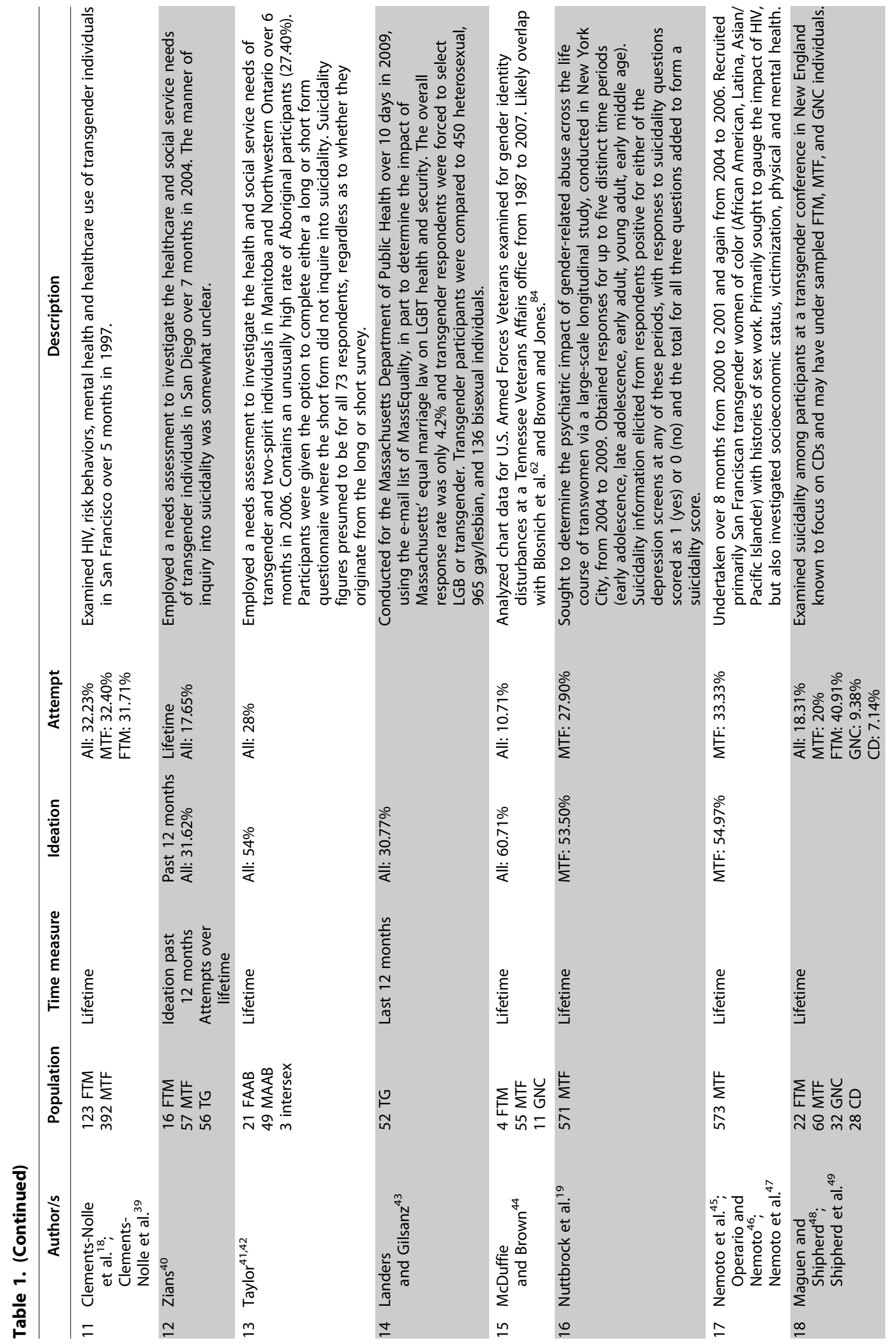




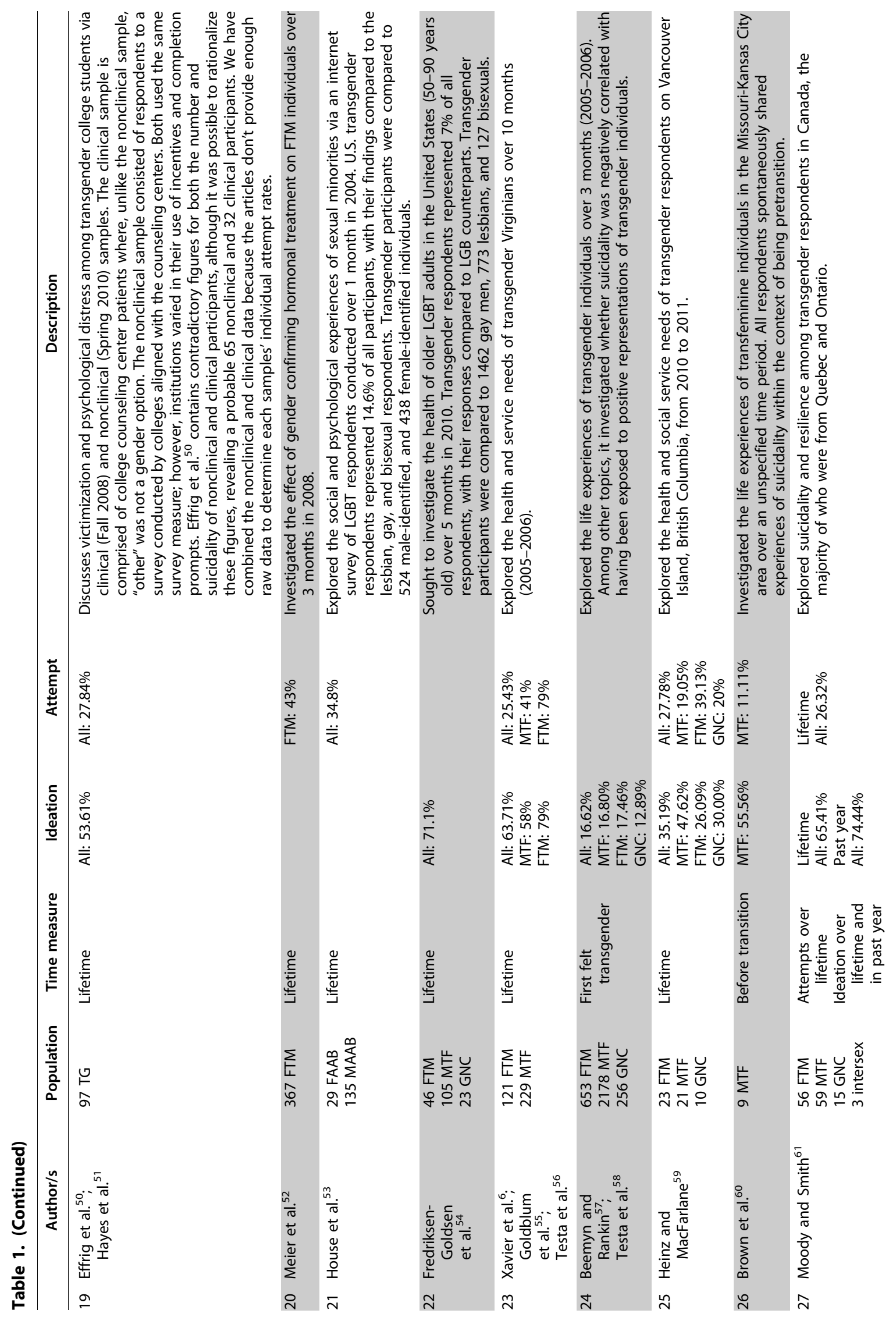




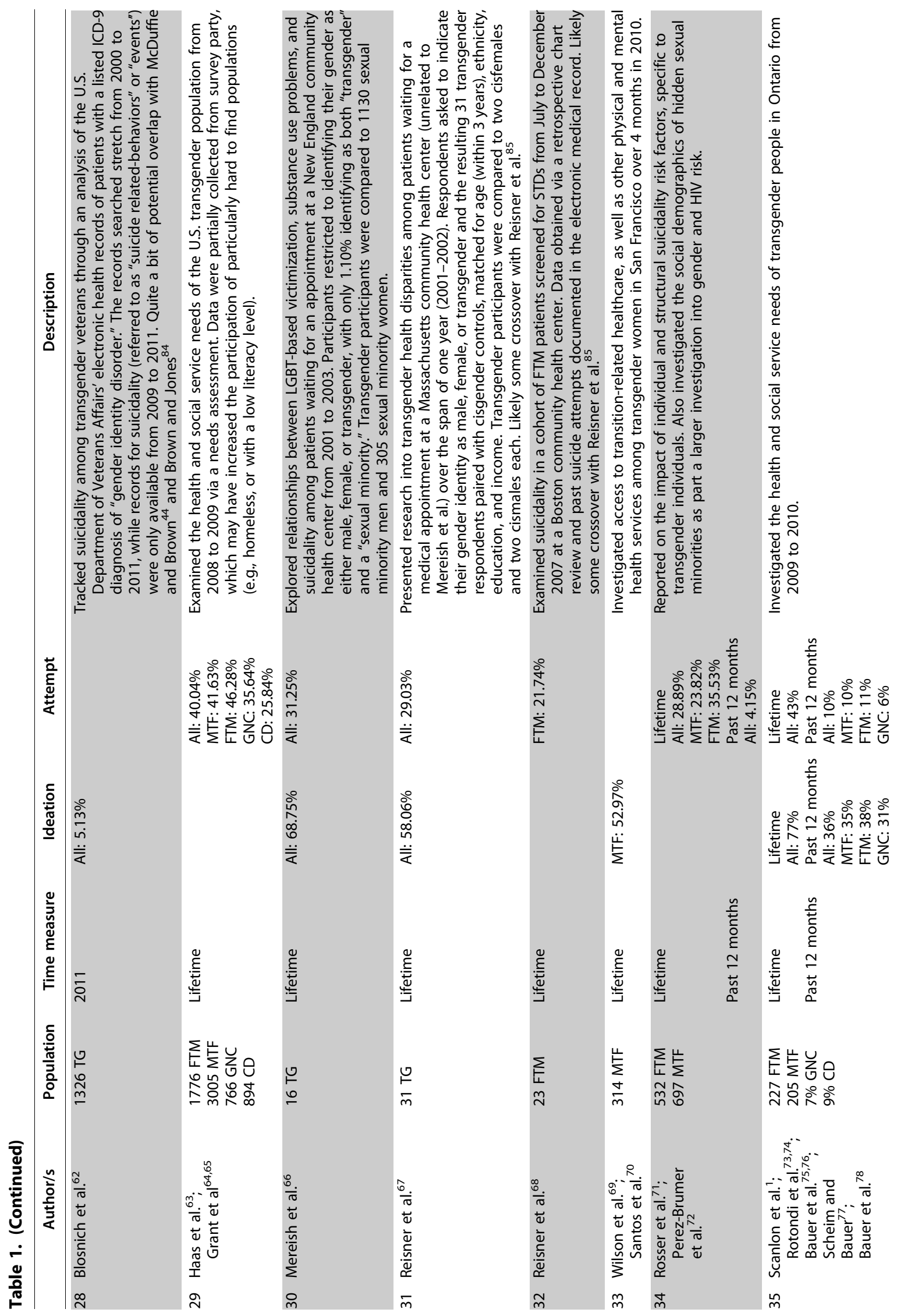




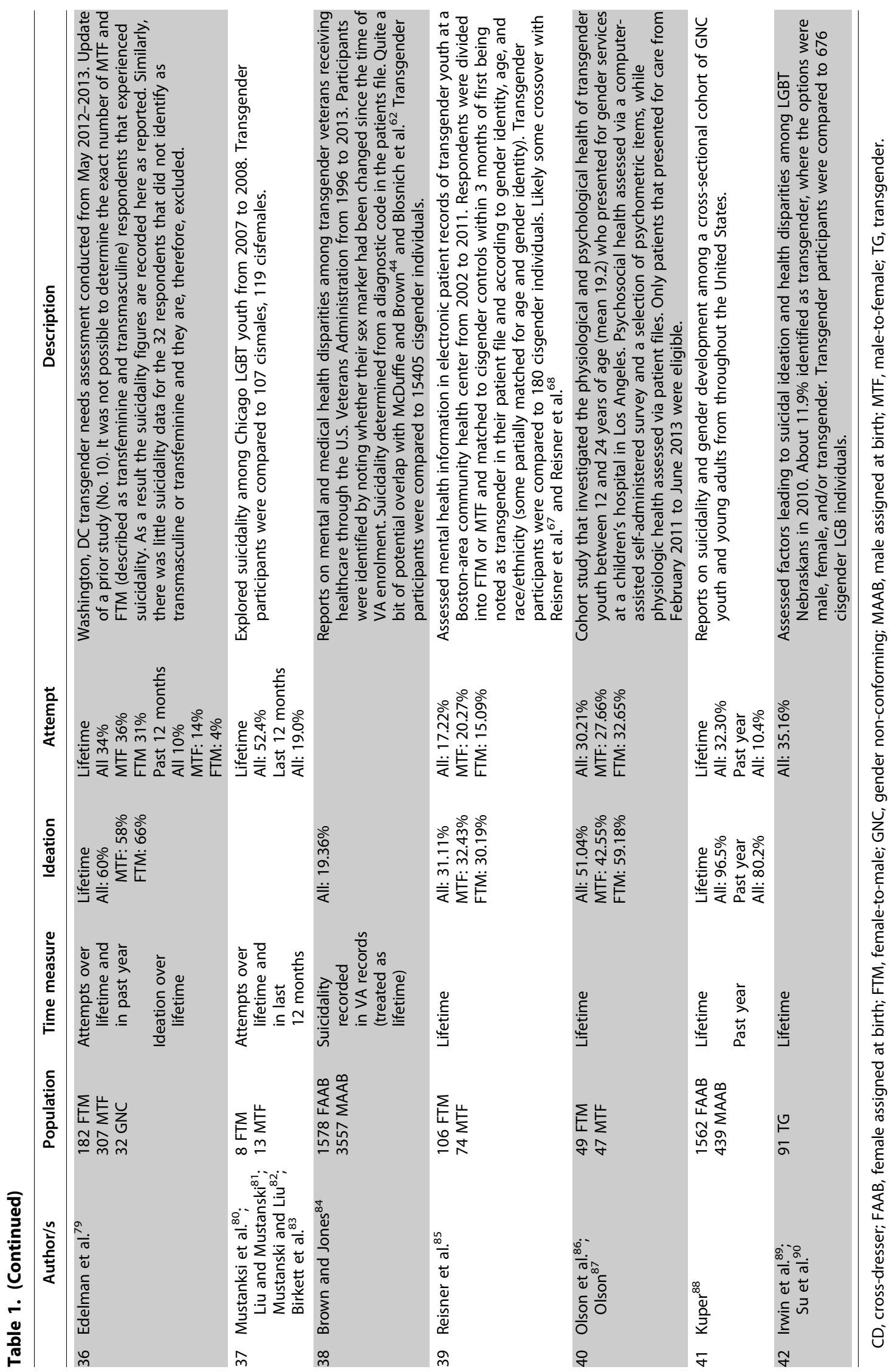


once, while the most recently published report was of primary import, though all reports published on a single study were reviewed for pertinent information. Finally, all included studies were reported in a primarily written format, thus excluding posters and other visual presentations.

\section{Data collection}

Rates of transgender suicidality were collected from included studies. Data absent from the included articles were supplemented by interviews with the study authors. However, to ensure the confidentiality promised as a condition of these interviews and required by the original Research Ethics Board approval, obtained through Dalhousie University, we have not indicated where this supplementation occurred.

Literature. Transgender suicidality literature was primarily identified via the WorldCat database because it is one of the largest global digital catalogs of cross-referenced and multi-disciplinary material. This search was supplemented with and cross-checked against results from Google Scholar and Google Search and later by manually reviewing the reference lists of identified articles, which resulted in the identification of a small number of additional articles. University of Calgary suicidality research Richard Ramsay's collated list of transgender suicidality studies was also invaluable. ${ }^{100}$ The following key terms were used when searching WorldCat, Google Scholar, and in Google Search; "transgender suicide"; "transsexual suicide"; "FTM suicide"; "MTF suicide"; "transsexual suicidality"; "transgender suicidality"; "transgender suicide attempt"; and "transsexual suicide attempt."

Of the 2016 records identified, 1005 duplicates were immediately eliminated. The titles and abstracts of the remaining articles were screened (Fig. 1). After excluding reference lists, non-English language publications, audiovisual reports, and those that did not mention transgender suicidality in either the title or the abstract, 311 articles remained. The full texts of these articles were reviewed. Those further eliminated include articles that reported no original data on transgender suicide attempts and/or ideation (105), meta-analyses/ reviews of transgender suicidality (10), those with no/ unclear quantitative data (42), articles published before 1997 (31), those not from the United States or Canada (43), those where the majority of participants were under 18 at the time of first data collection (5), and those with less than five participants (3). The remaining 72 articles, representing 42 distinct research studies (some published multiple times), were examined in the qualitative synthesis, while the 3 that reported suicidality as an amalgamate of ideation and attempts were excluded from the quantitative synthesis. ${ }^{32-33,62,84}$

\section{Data analysis}

The 42 studies on transgender suicidality are subjected here to a simple descriptive analysis, with the intention of summarizing the statistics on transgender suicidality included in the source research, and providing inroads to a more thorough examination in the future. To this end, individual studies' suicidality statistics (total number of participants, mean suicidality, range) were recalculated where possible using all study participants as a denominator. We considered but chose not to use only participants that responded to a given suicidality question because relatively few studies reported enough raw data to reliably and consistently calculate this figure. Similarly, we noted that the 42 studies differed in whether they reported ideation and attempts separately or in an amalgamate. We have compensated for this by separating these statistics where enough raw data are available to make this possible. Where this was not possible (three cases) we recorded the given figures as is and did not use them in subsequent calculations of cross-study suicidality averages. Note that, beyond these actions and the criteria set for inclusion on this meta-synthesis, no additional measures were taken to account for varying study designs.

After processing the individual studies as described, we combined their suicidality statistics and calculated the overall mean rate of suicidal ideation and attempts for the 39 that measured these as independent factors and excluding the 3 that combined these figures. Variation is operationalized in the current meta-synthesis as any difference between the calculated study ideation and attempt means and the overall ideation and attempt means for all studies included. After calculating these studies by comparing these means according to participants' gender identity and over time (ever, past year, and before treatment/transition/when participants first felt transgender). We also compared the range of suicidality figures reported by these studies. These calculations were conducted with the aid of Excel and SPSS v. 23.

\section{Results}

Methodologies and study design

Of the 42 studies analyzed here, $11.9 \%(n=5)$ were Canadian, with the remaining $88.1 \%(n=37)$ originating in the United States. Beginning with an average of 1 per 


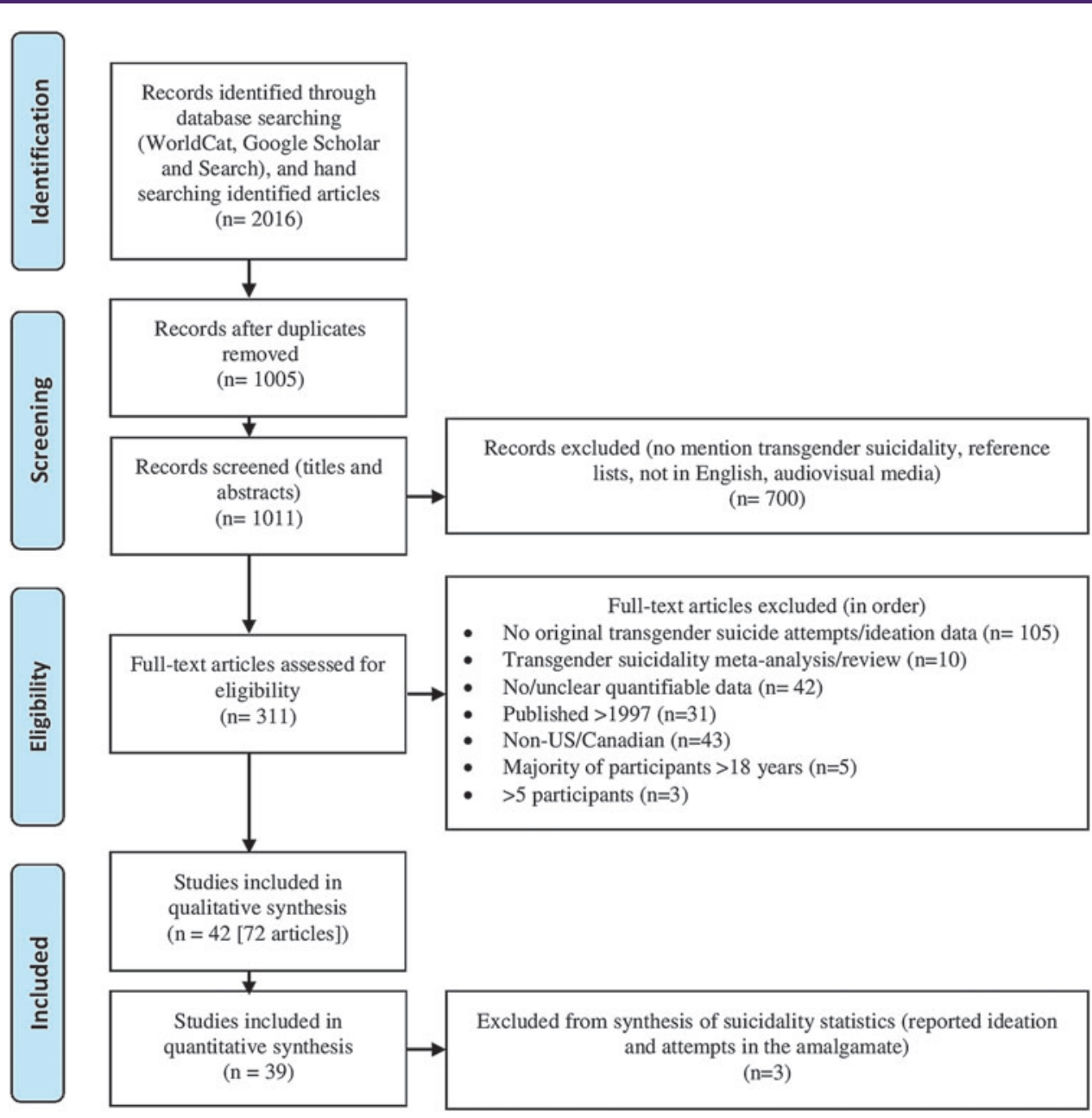

FIG. 1. A PRISMA ${ }^{101}$ flow chart showing the literature reviewed for this assessment of transgender suicidality and the process of narrowing its scope to those North American studies that reported original transgender suicidality data, were published since 1997, and included five or more participants who were majority 18 years of age or older $(50 \%+1)$.

year, there are now $\sim 4$ publications per year on this topic, with a high of 11 in 2011. Interestingly, despite the inclusion of gray literature, only six studies were solely published outside of a formal peer-reviewed format. Of these, one took the form of a thesis, while the remaining five were published in reports to communities, research granting agencies, governmental bodies, or as part of rigorous analyses by academic think tanks.

Eleven studies have included cisgender comparison or control groups, all of which were published since 2002 , and $82 \%(n=9)$ since 2009 . In comparing the research designs of all 42 studies, we see that $11.9 \%$ $(n=5)$ used case series, $59.5 \%(n=25)$ used crosssectional, 19\% used case control $(n=8)$, and $9.5 \%$ used cohort $(n=4)$ designs, with a marked increase in the latter two since 2009 ( $83 \%$ of 12 total). Additionally, $73.8 \%(n=31)$ of these studies took place in a nonclinical setting, $23.8 \%(n=10)$ in a clinical setting, and $2.4 \%(n=1)$ in combined clinical and nonclinical settings. Finally, four different methods of data collection were employed, with 69\% $(n=29)$ using self-administered questionnaires, $31 \%$ $(n=13)$ administered questionnaires, $14.3 \% \quad(n=6)$ face-to-face interviews, and $16.7 \%(n=7)$ chart reviews.

\section{Participant demographics}

The individual studies that make up this metasynthesis include from 9 to 6441 participants, for an 
estimated total of 25,735 transgender individuals. Of these, $\sim 4625$ could be distinctly classified as FTM, 9698 as male-to-female (MTF), 1377 as gender nonconforming (GNC), and 939 as CDs. The majority of participants were male assigned at birth (MAAB; $n=15,074$ vs. female assigned at birth [FAAB]; $n=8697$ ). Additionally, though inconsistently recorded and difficult to track, four studies reported on a total of 13 intersex participants (Table 1).

The majority of studies excluded all participants under 18 years of age $(n=32)$, though ${ }^{36-38,40,80-83,88}$ reported a minority under this age (2.94-33.3\%). In the remaining cases, ${ }^{1,28-30,43,50,51,73-78,85-87}$ while it was apparent that the majority of the sample was over 18 years at the time of participation, insufficient information was provided to determine the exact number and proportion of those under this age.

\section{Suicidality}

Of the 42 studies analyzed, $83 \%(n=35)$ asked participants about lifetime ideation and/or attempts, while $36 \%(n=15)$ measured suicidality specific to a particular period either instead of, or in addition to this. (In one case, suicidality was recorded over a period of 17 years, which was treated as lifetime suicidality in the following calculations.) In addition to different studies assessing either ideation and attempts during different time frames (e.g., lifetime or part year), several studies assessed both ideation and attempts over different periods (e.g., lifetime ideation, attempts in past year) and/or for different gender identities and/or sexes assigned at birth.

Suicidal ideation and attempts were typically reported separately; for example, $67 \%(n=28)$ of the studies assessed ideation and $81 \%(n=34)$ assessed attempts. Additionally, three studies $(7,28$, and 38 in Table 1) amalgamated ideation and attempts into a single figure, one of which investigated suicidality over the lifetime, one in the past 3 years, and one in 2011 alone. These three studies have therefore been excluded from the subsequent synthesis of suicidality statistics.

Lifetime suicidality. As seen in Figure 2, when suicidality statistics are averaged across all studies and analyzed by participants' gender identity, there is a tendency for MTF participants to ideate somewhat more often than FTM participants (51.7\% vs. $45.4 \%)$, while attempts are virtually identical ( $31 \%$ vs. $32.3 \%)$. GNC individuals appear to ideate $(30 \%)$ and attempt (25.6\%) less than MTF and FTM individuals, while

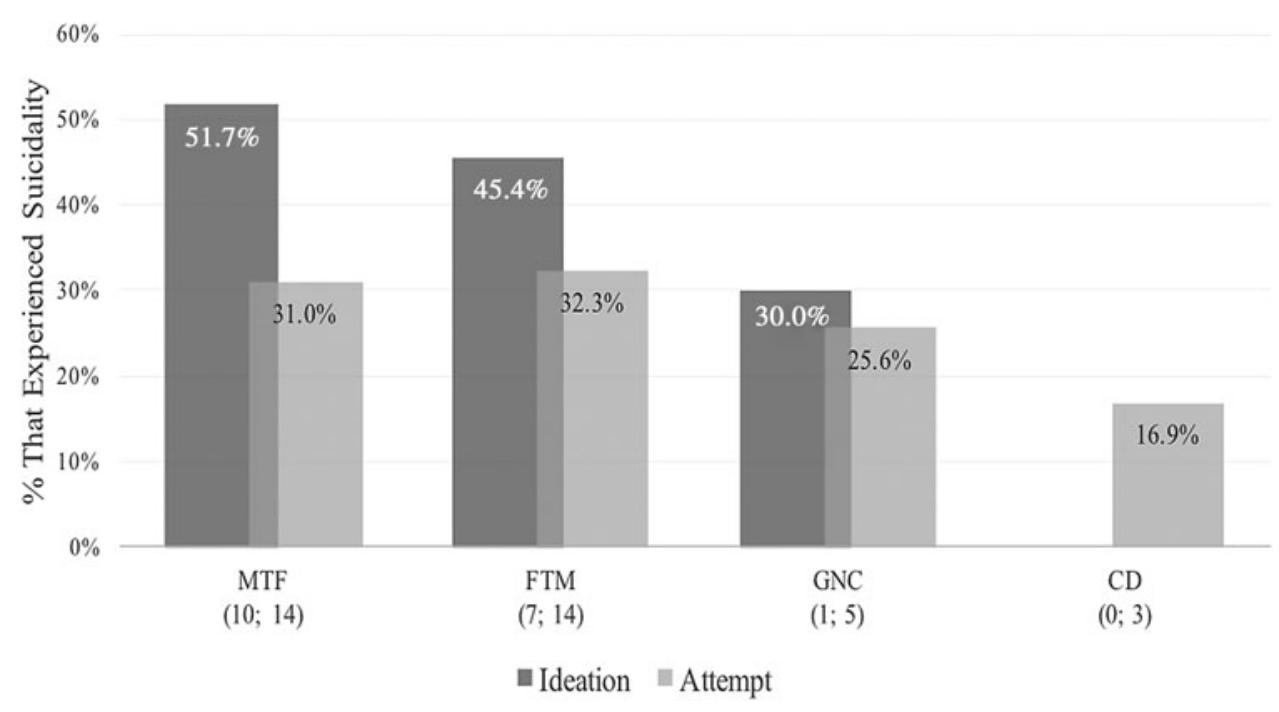

FIG. 2. Suicidality among transgender adults in studies that measured this across the lifetime, or "ever," as compared by gender identities. The numbers in brackets represent, first, the number of studies that recorded ideation statistics and second, the number that recorded attempt statistics. The label "All" indicates the figure for suicidality in studies that measured this among all participants, irregardless of gender identity. CD, cross-dresser; FTM, female-to-male; GNC, gender non-conforming; MTF, male-to-female. 
CD individuals experience perhaps the least suicidality of the four groups (16.9\% ideation).

Suicidality over a specific period. As seen in Figure 3, the most common time period used for measuring suicidality was over the lifetime ( $n=23$ for ideation; $n=32$ for attempts), followed by the past year ( $n=5$ for ideation; $n=5$ for attempts). Additionally, four studies measured suicidality surrounding transition (e.g., when participants first felt transgender, before treatment, before transition, and after surgery). Of this group, only the three ( $n=2$ for ideation; $n=2$ for attempts) that investigated suicidality before treatment, transition, or when participants first felt transgender (representing a combined total of 3531 individuals) could reasonably be compared. Finally, one study measured ideation in the past 30 days.

The overall lifetime rate of suicidal ideation $(M=55.5 \%$; range $=28.9-96.5 \%)$ and attempts $(M=$ $28.9 \%$; range $=10.7-52.4 \%)$ were calculated across the 23 and 32 studies for which these behaviors were, respectively, recorded. Similarly, we see the average and range of suicidality over the past year (ideation $M=50.6 \%$; range $=30.8-80.2 \%$; attempt $M=10.7 \%$; range $=4.2-19 \%)$. Of equal import, this data set dem- onstrates the average and range of suicidality before transition (ideation $M=36.1 \%$; range $=16.6-55.6 \%$; attempt $M=13.1 \%$; range $=11.1-15 \%)$.

\section{Discussion}

\section{Findings}

Methodologically speaking, much has changed within the period covered by this meta-synthesis. For example, there appears to have been an increase in methodological rigor, particularly in terms of study design and the use of comparison groups. Furthermore, the majority of transgender suicidality research now takes place in nonclinical environments, which is a marked contrast from the beginning of this period and the previous era. Demographically, these studies have included proportionately more MTF and MAAB participants than FTM/ FAAB, GNC, or CD. Interestingly, $\mathrm{CD}$ appears to be something of a remnant of an older period in North American transgender culture, no longer in widespread use, at least as seen in recent academic publications.

In the studies examined in the current metasynthesis, an average of $56 \%$ of participants experienced lifetime suicidal ideation and $29 \%$ had ever attempted suicide. Given the rate of suicidality in the general population, $0.5 \%{ }^{2}$ and $3.7 \%,{ }^{3}$ respectively, it

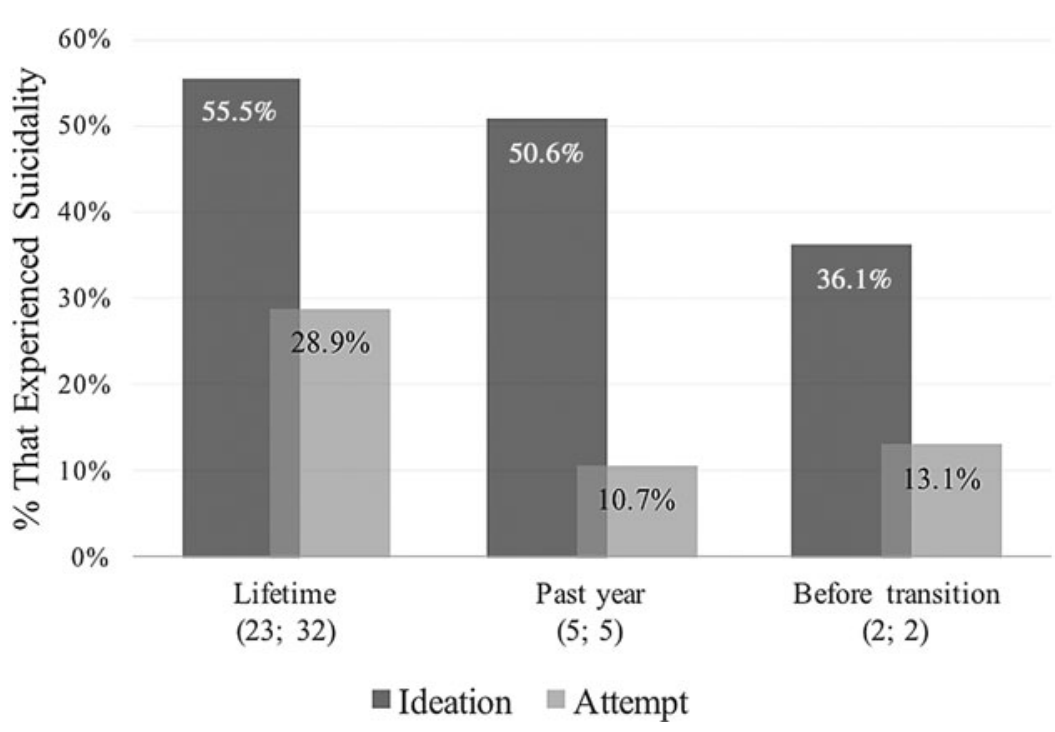

FIG. 3. Suicidality among transgender adults in studies that measured this in the past year, compared with those that measured this before transition. The numbers in brackets represent, first, the number of studies that recorded ideation statistics and second, the number that recorded attempt statistics. Studies that measured suicidality in "the past year" and "past 12 months" were combined. Little information was available for suicidality before transition (three studies total, two each for ideation and attempts) and the category is a combination of before treatment, when participants first felt trans, and before transition. 
is clear that transgender individuals are disproportionately impacted by this phenomenon. Indeed, even over the past year, where $51 \%$ of participants ideated and $11 \%$ attempted, suicidality is approximately 14 and 22 times higher than in the general public. MTF participants also appear to experience more ideation and roughly equal attempts as their FTM counterparts, though both groups ideate and attempt more than participants identified as GNC, followed by those identified as CD. Finally, the vast majority of studies explored suicidality at any point in a participants' lifetime, either in addition to, or instead of time-specific measures (past year, before transition). Of those that did record time-specific measures, the majority did so for the past year.

We can also theorize on the impact of time and transition on suicidality, though only in an exploratory fashion. For example, as expected, when we compare lifetime to past year suicidality we find that ideation (55\% vs. $51 \%)$ and especially attempts ( $29 \%$ vs. $11 \%)$ decrease. It seems counterintuitive, on the other hand, that suicide attempts are lower before transition (ideation 36.1\%; attempt 13.1\%) than over most other periods (past year attempts being the exception). However, we may expect to find higher rates of suicidality over the lifetime because this is a category that represents a non-transition specific and cumulative experience, in contrast to the single period represented by before transition. It may also be the case that individuals who do not desire transition represent a less dysphoric group and are therefore less suicidal. ${ }^{64}$ By contrast, evidence is mounting that barriers to transition-related healthcare contribute to suicidality among those who desire such measures ${ }^{63,78}$ and though it sometimes increases during transition, ${ }^{78}$ it typically decreases once desired transitional goals are completed. ${ }^{30,102}$ Indeed, a recent qualitative inquiry into suicide protective factors among trans adults identified several important protective factors among this population, one of which was socially and/or medically transitioning (for those who seek it). ${ }^{103}$ Additionally, suicidality may be generally higher among transgender individuals than the general population throughout the life course, due to factors unrelated to transition, such as stigma and discrimination. ${ }^{20,55,78}$

\section{Implications}

The results of the current meta-synthesis can inform a number of potential transgender healthcare strategies. For example, as noted above, there is growing evidence for the role of both antitransgender discrimination and transitional services in suicidality among this population, with the former implicated in heightened suicidality and the provision of the latter in its reduction. Physical healthcare providers may, therefore, find it advisable to reduce barriers to transition, while mental healthcare providers should be prepared to support transgender clients in seeking out, preparing for, and obtaining these services. Nevertheless, given the continued vulnerability of this population, mental healthcare practitioners should also be prepared to develop and reinforce this populations' resiliency against antitransgender stigma and discrimination, as well as prepare them for the possible increase of stress during transition. This may also include supporting and participating in policy and legislative measures arguing for transgender healthcare and human rights protections and decrying attempts to discriminate against this population (e.g., The American Psychiatric Association's Position Statement on Transgender and Gender Variant Individuals, ${ }^{104}$ The American Medical Associations' resolution on Removing Financial Barriers to Care for Transgender Patients, ${ }^{105}$ and the American Academy of Pediatrics Statement in Opposition of Legislation that Discriminates Against Transgender Children). ${ }^{106}$

\section{Limitations}

The results of this meta-synthesis are very preliminary and there are a number of limitations inherent to a study of this kind, relying as it does on datasets that are methodologically varied. For example, relatively few studies reported on lifetime suicidality among individuals identified as GNC and $\mathrm{CD}$, with the result that the analysis here is limited in generalizability. Similarly, relatively few studies measured suicidality either before transition or in the past year and it was, therefore, necessary to amalgamate several similar categories into the before transition group (before treatment, when participants first felt trans, and before transition). As noted, beyond the criteria set for an individual study's inclusion in this meta-synthesis and the actions taken to account for variation in their calculation of suicidality, no additional measures were taken to account for varying study designs and methodology.

Similarly, as is true within the broader field of transgender health, definitions of gender identity vary widely across these 42 studies. While documentation of nonbinary identities has increased in recent years ${ }^{107}$ researchers continue to struggle to account 
for the diversity among nonbinary individuals or respond to the rapid shifts in acceptable and preferred language within this community. ${ }^{108}$

The manner in which researchers inquired about suicidality is also concerning. For example, some research$\mathrm{ers}^{63}$ note that yes/no questions, such as "have you ever attempted suicide?" tend to overestimate positive responses from those who have self-harmed, but not attempted to end their life. This might be corrected by questioning participants' intent to die through in-person interviews, which have been found to reduce attempt rates from $4.6 \%$ to $2.7 \%$ of an adult sample. ${ }^{109,110}$ Unfortunately, only $14 \%$ of the 42 studies included here collected data primarily from face-to-face interviews.

\section{Future research}

There is a lack of research into transgender people's experiences of minority stress ${ }^{111}$ and resiliency ${ }^{61}$ particularly the impact of transition-related interventions on suicidality. ${ }^{52}$ Researchers may also wish to include an additional measure reflecting current lived gender presentation which, owing to prejudice and/or other practical concerns, may differ from ones' core identity. It may also be the case that participants' gender identity evolves and shifts, and it is therefore difficult to capture this without asking participants to account for all previously held identities, rather than just that held in the moment of data collection.

Additionally, researchers might also explore the potential for bias in studies conducted in clinical environments, as participants may be dependent on the clinical environment for transition-related care. Consistent with social desirability bias, asking about suicidality in these environments, especially if not anonymously, may reinforce a transitional narrative where participants feel pressured to give a more positive picture of their mental health for fear of being denied, losing, or being forced to wait longer than necessary for lifesaving transition-related services ${ }^{112,113}$ Indeed, the practice of delaying transitional treatment due to comorbid symptomatology like depression and suicidality is widely practiced, ${ }^{114}$ though evidence is mounting against the efficacy and ethics of this approach. ${ }^{78}$ While set guidelines for transgender suicidality research would help to address this and other concerns, such a tool might not be help to address the expectation of bias created by the optics of the situation (e.g., that patients may not feel comfortable sharing their experiences of suicidality with those responsible for their care, where they are suspected to impact it).
Several decades of research have been conducted regarding suicidality experienced by transgender individuals. As summarized in the current meta-synthesis, rates of both ideation and attempts vary a great deal in subgroups of transgender individuals (FTM, MTF, GNC, CD), and based on several factors (e.g., type of questions asked, data collection method). The current meta-synthesis is the first of its kind to summarize 19 years of this important research and make sense of the 42 studies published in that time. It is our hope that the current article is a small but important addition to the body of knowledge regarding transgender suicidality and that the results may be used to inform future research and best practices.

\section{Author Disclosure Statement}

No competing financial interests exist.

\section{References}

1. Scanlon K, Travers R, Coleman T, et al. Ontario's trans communities and suicide: transphobia is bad for our health. TransPULSE. 2010. Available at www.transpulseproject.ca/wp-content/uploads/2010/11/E2English.pdf (accessed April 4, 2017).

2. Centers for Disease Control and Prevention. Suicide facts at a glance: 2012. CDC Stacks: Public Health Publications. Centers for Disease Control. 2012. Available at https://stacks.cdc.gov/view/cdc/21865 (accessed April 4, 2017).

3. Statistics Canada. Table 11: Suicidal thoughts, by age group and sex, household population aged 15 and over, Canada excluding territories, 2002. Statistics Canada. 2004. Available at www.statcan.gc.ca/pub/82617-x/htm/4067670-eng.htm (accessed April 4, 2017).

4. Haas AP, Eliason M, Mays VM, et al. Suicide and suicide risk in lesbian, gay, bisexual, and transgender populations: review and recommendations. J Homosex. 2010;58:10-51.

5. de Wilde EJ. Qualitative research in suicidology: still a well-disguised blessing? Arch Suicide Res. 2002;6:55-59.

6. Xavier J, Honnold JA, Bradford J. The Health, Health-Related Needs, and Life Course Experiences of Transgender Virginians. Richmond, VA: Virginia HIV Community Planning Committee and Virginia Department of Health, 2007. Available at www.vdh.virginia.gov/content/uploads/sites/ 10/2016/01/THISFINALREPORTVol1.pdf (accessed April 4, 2017).

7. Imbimbo C, Verze $P$, Palmieri A, et al. A report from a single institute's 14year experience in treatment of male-to-female transsexuals. J Sex Med. 2009;6:2736-2745.

8. Bockting W. Transforming the paradigm of transgender health: a field in transition. Sex Relation Ther. 2009;24:103-107.

9. Hamburger C, Sturup G, Dahl-Iversen E. Transvestism: hormonal, psychiatric, and surgical treatment. J Am Med Assoc. 1953;152.

10. Edgerton MT, Meyer JK. Surgical and psychiatric aspects of transsexualism. In: Surgery of the External Genitalia (Horton C; ed). Boston: Little Brown \& Company, 1973, pp. 117-161.

11. Hunt DD, Hampson JL. Follow-up of 17 biologic male transsexuals after sex-reassignment surgery. Am J Psychiatry. 1980;137:432-438.

12. Lothstein LM. The aging gender dysphoria (transsexual) patient. Arch Sex Behav. 1979;8:431-444.

13. Stoller RJ. Sex and Gender: The Development of Masculinity and Femininity. London: Karnac Books, 1968.

14. Pierce DK. The adjustment of female transsexuals following surgical and hormonal sex reassignment [Thesis]. Rutgers, New Jersey: Rutgers University, 1977.

15. Michel A, Ansseau M, Legros JJ, et al. The transsexual: what about the future. Eur Psychiatry. 2002;17:353-362.

16. Mate-Kole C, Freschi M, Robin A. Aspects of psychiatric symptoms at different stages in the treatment of transsexualism. Br J Psychiatry. 1988; 152:550-553. 
17. Devor H. Female to Male Transsexuals in Society. Bloomington: Indiana University Press, 1997.

18. Clements-Nolle K, Marx R, Katz M. Attempted suicide among transgender persons. J Homosex. 2006;51:53-69.

19. Nuttbrock L, Hwahng S, Bockting W, et al. Psychiatric impact of genderrelated abuse across the life course of male-to-female transgender persons. J Sex Res. 2010;47:12-23.

20. Dhejne $C$, Lichtenstein $P$, Boman $M$, et al. Long-term follow-up of transsexual persons undergoing sex reassignment surgery: cohort study in Sweden. PLoS One. 2011;6:1-8.

21. Richmond K, Carroll K, Denboske K. Gender identity disorder: concerns and controversies. In: Handbook of Gender Research in Psychology (Chrisler JC, McCreary DR; eds). New York: Springer Science + Business Media, 2010, 111-131.

22. Kruijver FPM, Zhou J-N, Pool CW, et al. Male-to-female transsexuals have female neuron numbers in a limbic nucleus. J Clin Endocrinol Metab. 2000;85:2034-2041.

23. Marshall E, Claes L, Bouman WP, et al. Non suicidal self injury and suicidality in trans people: a systematic review of the literature. Int Rev Psychiatry. 2015;28:1-12.

24. Cole CM, O'Boyle MO, Emory LE, Meyer WJ. Comorbidity of gender dysphoria and other major psychiatric diagnoses. Arch Sex Behav. 1997;26:13-26.

25. Devor H. Transsexualism, dissociation, and child abuse: an initial discussion based on nonclinical data. J Psychol Human Sex. 1994;649-72.

26. Rehman J, Lazer $S$, Benet $A E$, et al. The reported sex and surgery satisfactions of 28 postoperative male-to-female transsexual patients. Arch Sex Behav. 1999;28:71-89.

27. Mathy RM. Transgender identity and suicidality in a nonclinical sample: sexual orientation, psychiatric history, and compulsive behaviours. J Psychol Human Sex. 2002;14:47-65.

28. Singer TB, Cochran M, Adamec R. Final report by the Transgender Health Action Coalition (THAC) to the Philadelphia Foundation Legacy Fund. 1997. Philadelphia, PA: Transgender Health Action Coalition.

29. Kenagy GP. Exploring an oppressed group: a study of the health and social service needs of transgendered people in Philadelphia [Dissertation]. Philadelphia, Pennsylvania: University of Pennsylvania, 1998.

30. Kenagy GP. The health and social service needs of transgender people in Philadelphia. Int J Transgend. 2005;8:49-56.

31. Kenagy GP, Bostwick WB. Health and social service needs of transgender people in Chicago. Int J Transgend. 8, 57-66.

32. Bockting $W$, Huang $C-Y$, Ding $H$, et al. Are transgender persons at higher risk for HIV than other sexual minorities? A comparison of HIV prevalence and risks. Int J Transgend. 2005;8:123-131.

33. Bockting W, Robinson B, Forberg J, Scheltema K. Evaluation of a sexual health approach to reducing HIV/STD risk in the transgender community. AIDS Care. 2005;17: 289-303.

34. Kenagy GP. Transgender health: findings from two needs assessment studies in Philadelphia. Health Soc Work. 2005;30:19-26.

35. Risser JMH, Shelton A, McCurdy S, et al. Sex, drugs, violence, and HIV status among male-to-female transgender persons in Houston, Texas. Int J Transgend, 2005;8:67-74

36. Xavier JM. The Washington, DC Transgender Needs Assessment Survey: Final Report for Phase Two. Washington, DC: Administration for HIV and AIDS of the District of Columbia Government, 2000.

37. Xavier JM, Simmons R. The Washington Transgender Needs Assessment Survey: executive summary. Washington, DC: Administration for HIV and AIDS of the District of Columbia Government, 2000. Available at www.glaa.org/archive/2000/tgneedsassessment1112.shtm (accessed April 4, 2017).

38. Xavier JM, Bobbin MB, Singer B, Budd E. A needs assessment of transgendered people of color living in Washington, DC. Int J Transgend. 2005;8:31-47.

39. Clements-Nolle K, Marx R, Guzman R, Katz M. HIV prevalence, risk behaviours, health care use, and mental health status of transgender persons: implications for public health intervention. Am J Public Health. 2001;91:915-921.

40. Zians J. The San Diego County Transgender Assessment Report. San Diego, CA: The California Endowment and Family Health Centers of San Diego's Transgender Health Project, 2006.

41. Taylor C. Nowhere Near Enough: A Needs Assessment of Health and Safety Services for Transgender and Two Spirit People in Manitoba and
Northwestern Ontario. Winnipeg, Manitoba: Crime Prevention Branch Public Safety and Emergency Preparedness Canada, 2006. Available at www.turtleisland.org/discussion/viewtopic.php? $p=7927$ (accessed April 4, 2017).

42. Taylor $C$. Health and safety issues for aboriginal transgender/two spirit people in Manitoba. Canadi J Aborig Community Based HIV/AIDS Res. 2009;2:63-84.

43. Landers SJ, Gilsanz P. The Health of Lesbian, Gay, Bisexual and Transgender (LGBT) Persons in Massachusetts: A Survey of Health Issues Comparing LGBT Persons with Their Heterosexual and Non-transgender Counterparts. Boston, MA: Massachusetts Department of Public Health 2009. Available at www.masstpc.org/wp-content/uploads/2012/10/ DPH-2009-lgbt-health-report.pdf (accessed April 4, 2017).

44. McDuffie E, Brown GR. 70 U.S. veterans with gender identity disturbances: a descriptive study. Int J Transgend. 2010;12:21-30.

45. Nemoto T, Keatley JG, Operario D, Soma T. Psychosocial Factors Affecting HIV Risk Behaviours Among Male-to-Female Transgenders (MTF TGs) in San Francisco. San Francisco, CA: The University of California, San Francisco Center for AIDS Prevention Studies [CAPS], 2002.

46. Operario D, Nemoto T. Sexual risk behavior and substance use among a sample of Asian Pacific Islander transgendered women. AIDS Educ Prev. 2005;17:430-443.

47. Nemoto T, Bodeker B, Iwamoto M. Social support, exposure to violence and transphobia and correlates of depression among male-to-female transgender women with a history of sex work. Am J Public Health. 2011;101:1980-1988.

48. Maguen S, Shipherd JC. Suicide risk among transgender individuals. Psychol Sex. 2010;1:34-43.

49. Shipherd JC, Maguen S, Skidmore WC, Abramovitz SM. Potentially traumatic events in a transgender sample: frequency and associated symptoms. Traumatology. 2011;17:56-67.

50. Effrig JC, Bieschke KJ, Locke BD. Examining victimization and psychological distress in transgender college students. J Coll Couns. 2011;14:143-157.

51. Hayes JA, Locke BD, Castonguay LG. Introduction to the special issue: the centre for collegiate mental health: practice and research working together. J Coll Couns. 2011;14:101-104.

52. Meier SLC, Fitzgerald KM, Pardo ST, Babcock J. The effects of hormona gender affirmation treatment on mental health in female-to-male transsexuals. J Gay Lesbian Ment Health. 2011;15:281-299.

53. House AS, Van Horn E, Coppeans C, Stepleman LM. Interpersonal trauma and discriminatory events as predictors of suicidal and nonsuicidal self-injury in gay, lesbian, bisexual, and transgender persons. Traumatology. 2011;17:75-85

54. Fredriksen-Goldsen $\mathrm{KI}$, Kim $\mathrm{H}$, Emlet $\mathrm{CA}$, et al. The Aging and Health Report: Disparities and Resilience Among Lesbian, Gay, Bisexual, and Transgender Older Adults. Seattle, WA: Institute for Multigenerational Health, 2011.

55. Goldblum P, Testa RJ, Pflum S, et al. The relationship between genderbased victimization and suicide attempts in transgender people. Prof Psychol Res Pract. 2012;43:468-475.

56. Testa RJ, Sciacca LM, Wang F, et al. Effects of violence on transgender people. Prof Psychol Res Pract. 2012;43:452-459.

57. Beemyn G, Rankin S. The Lives of Transgender People. New York, NY: Columbia University Press, 2011.

58. Testa RJ, Jimenez $\mathrm{CL}$, Rankin $\mathrm{S}$. Risk and resilience during transgender identity development: the effects of awareness and engagement with other transgender people on affect. J Gay Lesbian Ment Health. 2013;18:31-46.

59. Heinz M, MacFarlane D. Island lives: a trans community needs assess ment for Vancouver Island. SAGE Open. 2013;3:1-13.

60. Brown C, Dashjian LT, Acosta TJ, et al. Learning from the life experiences of male-to-female transsexuals. J GLBT Fam Study. 2013;9: 105-128.

61. Moody C, Smith NG. Suicide protective factors among trans adults. Arch Sex Behav. 2013:42:739-752.

62. Blosnich JR, Brown R, Shipherd JC, et al. Prevalence of gender identity disorder and suicide risk among transgender veterans utilizing veterans health administration care. Am J Public Health. 2013;103:e27-e32.

63. Haas AP, Rodgers PL, Herman J, et al. Suicide Attempts Among Transgender and Gender Non-conforming Adults: Findings of the National Transgender Discrimination Survey. Los Angeles, CA: The Williams 
Centre, 2014. Available at https://williamsinstitute.law.ucla.edu/ wp-content/uploads/AFSP-Williams-Suicide-Report-Final.pdf (accessed April 4, 2017).

64. Grant JM, Mottet LA, Tanis J, et al. National Transgender Discrimination Survey Report on Health and Health Care. Washington, DC: National Center for Transgender Equality and National Gay and Lesbian Task Force, 2010. Available at www.thetaskforce.org/static_html/downloads/ resources_and tools/ntds report on health.pdf (accessed April 4, 2017).

65. Grant JM, Mottet LA, Tanis J, et al. Injustice at Every Turn: A Report of the National Transgender Discrimination Survey. Washington, DC: National Center for Transgender Equality and National Gay and Lesbian Task Force, 2011. Available at www.thetaskforce.org/static_html/downloads/ reports/reports/ntds_full.pdf (accessed April 4, 2017).

66. Mereish $\mathrm{EH}, \mathrm{O}^{\prime}$ Cleirigh $\mathrm{C}$, Bradford JB. Interrelationships between LGBT based victimization, suicide, and substance use problems in a diverse sample of sexual and gender minorities. Psychol Health Med. 2014;19: $1-13$.

67. Reisner SL, White JM, Bradford JB, Mimiaga MJ. Transgender health disparities: comparing full cohort and nested matched-pair study designs in a community health center. LGBT Health. 2014;1:177-184.

68. Reisner SL, White JM, Mayer KH, Mimiaga MJ. Sexual risk behaviors and psychosocial health concerns of female-to-male transgender men screening for STDs at an urban community health center. AIDS Care. 2014;26:857-864.

69. Wilson EC, Chen, $\mathrm{Y}-\mathrm{H}$, Arayasirikul $\mathrm{S}$, et al. Connecting the dots: examining transgender women's utilization of transition-related medical care and associations with mental health, substance use, and HIV. J Urban Health. 2014;92:182-192.

70. Santos GM, Rapues J, Wilson EC, et al. Alcohol and substance use among transgender women in San Francisco: prevalence and association with human immunodeficiency virus infection. Drug Alcohol Rev. 2014;33:287-295.

71. Rosser BRS, Oakes JM, Bockting WO, Miner M. Capturing the social demographics of hidden sexual minorities: an internet study of the transgender population in the United States. Sex Res Soc Policy. 2007;4:50-64.

72. Perez-Brumer A, Hatzenbuehler ML, Oldenburg CE, Bockting W. Individual and structural-level risk factors for suicide attempts in transgender adults. Behav Med. 2015;41:164-171.

73. Rotondi NK, Bauer GR, Travers R, et al. Depression in male-to-female transgender Ontarians: results from the trans PULSE project. Can J Commun Ment Health. 2011;30:113-133.

74. Rotondi NK, Bauer GR, Scanlon K, et al. Prevalence of and risk and protective factors for depression in female-to-male transgender Ontarians: trans PULSE project. Can J Commun Ment Health. 2011;30:135-155.

75. Bauer G, Anjali K, Pyne J, et al. Improving the health of trans communities: findings from the trans PULSE project. Presented at Rainbow Health Ontario Conference, Ottawa, Ontario, Canada, March 22, 2012.

76. Bauer GR, Pyne J, Francino MC, Hammond R. Suicidality among trans people in Ontario: implications for social work and social justice. Serv Soc. 2013;59:35-62.

77. Scheim Al, Bauer GR. Sex and gender diversity among transgender persons in Ontario, Canada: results from a respondent-driven sampling surgery. J Sex Res. 2014;0:1-14.

78. Bauer GR, Scheim Al, Pyne J, et al. Intervenable factors associated with suicide risk in transgender persons: a respondent driven sampling study in Ontario, Canada. BMC Public Health. 2015;15:1-15.

79. Edelman EA, Corado R, Lumby, et al. Access Denied: Washington, DC Trans Needs Assessment Report. Washington, DC: DC Trans Coalition, 2015.

80. Mustanksi BS, Garofalo R, Emerson EM. Mental health disorders, psychological distress, and suicidality in a diverse sample of lesbian, gay, bisexual and transgender youths. Am J Public Health. 2010;100:24262432.

81. Liu RT, Mustanski B. Suicidal ideation and self-harm in gay, bisexual, and transgender youth. Am J Prev Med. 2012;42:221-228

82. Mustanski B, Liu RT. A longitudinal study of predictors of suicide attempts among lesbian, gay, bisexual, and transgender youth. Arch Sex Behav. 2013;42:437 448.
83. Birkett M, Newcomb ME, Mustanski B. Does it get better? A longitudinal analysis of psychological distress and victimization in lesbian, gay, bisexual, transgender, and questioning youth. J Adolesc Health. 2015;56:280-285.

84. Brown GR, Jones KT. Mental health and medical health disparities in 5135 transgender veterans receiving healthcare in the Veterans Health Administration: a case control study. LGBT Health. 2015;0:1-10.

85. Reisner SL, Vetters $\mathrm{R}$, Leclerc $\mathrm{M}$, et al. Mental health of transgender youth in care at an adolescent urban community health center: a matched retrospective cohort study. J Adolesc Health. 2015;56:1-6.

86. Olson J, Schrager SM, Belzer M, et al. Baseline physiologic and psychosocial characteristics of transgender youth seeking care for gender dysphoria. J Adolesc Health. 2015;57:374-380.

87. Olson JL. Baseline physiologic and psychosocial characteristics of transgender youth seeking care for gender dysphoria [Dissertation]. Los Angeles, California: University of Southern California, 2015.

88. Kuper LE. Gender development and suicidality among transgender and gender non-conforming youth and young adults [Dissertation]. Chicago, Illinois: University of Illinois at Chicago, 2015.

89. Irwin JA, Coleman JD, Fisher CM, Marasco VM. Correlates of suicide ideation among LGBT Nebraskans. J Homosex. 2014;61:1172-1191.

90. Su D, Irwin JA, Fisher C, Ramos A, et al. Mental health disparities within the LGBT population: a comparison between transgender and nontransgender individuals. Transgender Health. 2016;1: $12-20$.

91. Meads C, Pennant M, McManus J, Bayliss S. A Systematic Review of Lesbian, Gay, Bisexual and Transgender Health in the West Midlands Region of the UK Compared to Published UK Research. Birmingham, England: West Midlands Health Technology Assessment Collaboration [WMHTAC] and The University of Birmingham's Unit of Public Health, Epidemiology and Biostatistics, 2009. Available at www.birmingham .ac.uk/Documents/college-mds/haps/projects/WMHTAC/ REPreports/2009/LGBThealth030409finalversion.pdf (accessed April 4, 2017).

92. Herbst JH, Jacobs ED, Finlayson TJ, et al. Estimating HIV prevalence and risk behaviors of transgender persons in the United States: a systematic review. AIDS Behav. 2008;12:1-17.

93. Pauly IB. Male psychosexual inversion: transsexualism: A review of 100 cases. Arch Gen Psychiatry. 1965;13:172-181.

94. Pauly IB. Female transsexualism: part I. Arch Sex Behav. 1974;3:487-507.

95. Pauly IB. Female transsexualism: part II. Arch Sex Behav. 1974;3:509-526.

96. Pauly IB. Outcome of sex reassignment surgery for transsexuals. Aust N Z J Psychiatry. 1981;15:45-51.

97. Wessex Institute for Health Research and Development. Surgical Gender Reassignment for Male to Female Transsexual People. Southampton, United Kingdom: Wessex Institute for Health Research and Development, 1998.

98. Lundström B, Pauly I, Walinder J. Outcome of sex reassignment surgery. Acta Psychiatr Scand. 1984;70:289-294.

99. Singh AA, Dickey LM. Affirmative Counseling and Psychological Practice with Transgender and Gender Nonconforming Clients. Washington, DC: American Psychological Association, 2017.

100. Ramsay RF. Transgender people generally have the highest 'attempted suicide' incidences among sexual minority groups. Increasing Awareness of GLBTTSQQA Suicide Issues. University of Calgary. Available at https://people.ucalgary.ca/ ramsay/transgender-transsexual-suicidestudies-world.htm (accessed April 4, 2017).

101. Moher D, Liberati A, Tetzlaff J, et al. Preferred reporting items for systematic reviews and meta-analyses: the PRISMA Statement. PLoS Med. 2009;6.

102. Keo-Meier $\mathrm{CL}$, Herman $\mathrm{LI}$, Reisner $\mathrm{SL}$, et al. Testosterone treatment and MMPI-2 improvement in transgender men: a prospective controlled study. J Consult Clin Psychol. 2015;83:143-156.

103. Moody C, Fuks N, Peláez S, Smith NG. "Without this, I would for sure already be dead": a qualitative exploration of trans individuals' suicidal ideation and factors that protect against suicide attempts. Psychol Sex Orientat Gend Divers. 2015;2:266-280.

104. Drescher J, Haller E; the APA Caucus of Lesbian, Gay and Bisexual Psychiatrists. Position Statement on Discrimination Against Transgender and Gender Variant Individuals. Washington, DC: American Psychiatric Association, 2012. Available at www.dhcs.ca.gov/services/MH/ 
Documents/2013_04_AC_06d_APA_ps2012_Transgen_Disc.pdf (accessed April 4, 2017).

105. American Medical Association. Removing financial barriers to care for transgender patients. 2008. Available at www.tgender.net/taw/ ama_resolutions.pdf (accessed April 4, 2017).

106. American Academy of Pediatrics. Statement in opposition of legislation that discriminates against transgender children. 2016. Available at www.aap.org/en-us/about-the-aap/aap-press-room/Pages/ AAPOpposesLegislationAgainstTransgenderChildren.aspx (accessed April 4, 2017).

107. Richards C, Bouman WP, Seal L, T'Sjoen G. Non-binary or genderqueer genders. Int Rev Psychiatry. 2016;28:1-8.

108. The World Professional Association for Transgender Health. (2011). Standards of Care for the Health of Transsexual, Transgender, and Gender Nonconforming People (7th ed.). Minneapolis: MN, 2011. Available at www.wpath.org/site_page.cfm?pk_association_webpage menu=1351\&pk_association_webpage $=3926$ (accessed April 4, 2017)

109. Kessler RC, Borges G, Walters EE. Prevalence of and risk factors for lifetime suicide attempts in the National Comorbidity Survey. Arch Gen Psychiatry. 1999;56:617-626.

110. Nock MK, Kessler RC. Prevalence of and risk factors for suicide attempts versus suicide gestures: analysis of the National Comorbidity Survey. J Abnorm Psychol. 2006;115:616-623.

111. Claes L, Bouman WP, Witcomb G, et al. Non-suicidal self-injury in trans people: associations with psychological symptoms, victimization, interpersonal functioning, and perceived social support. J Sex Med. 2015;12:168-179.
112. Marshall BDL, Socias ME, Kerr T, et al. Prevalence and correlated of lifetime suicide attempts among transgender persons in Argentina. J Homosex. 2015;63:955-967.

113. McNeil J, Bailey L, Ellis S, et al. Trans Mental Health Study 2012. 2012. Edinburgh, United Kingdom: Scottish Transgender Alliance. Available at www.gires.org.uk/assets/Medpro-Assets/trans_mh_study.pdf (accessed April 4, 2017).

114. Smith YLS. (2002). Sex reassignment: predictors and outcomes of treatment for transsexuals [Dissertation]. Utrecht, The Netherlands: Utrecht University, 2002.

Cite this article as: Adams N, Hitomi M, Moody C (2017) Varied reports of adult transgender suicidality: synthesizing and describing the peer reviewed and gray literature, Transgender Health 2:1, 60-75, DOI: 10.1089/trgh.2016.0036

\section{Publish in Transgender Health}

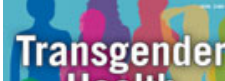

Health

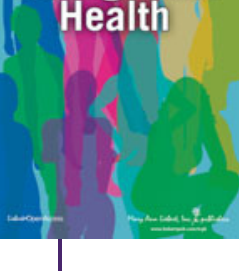

\section{Abbreviations Used}

$C D=$ cross-dressers

$F A A B=$ female assigned at birth

$\mathrm{FTM}=$ female-to-male

$\mathrm{GNC}=$ gender non-conforming

$M A A B=$ male assigned at birth

$\mathrm{MTF}=$ male-to-female
- Immediate, unrestricted online access

- Rigorous peer review

- Compliance with open access mandates

- Authors retain copyright

- Highly indexed

- Targeted email marketing

liebertpub.com/trgh 